\title{
Al-Pancasila fi al-Mandzûri al-Maqâshidî al-Syar'î: Dirâsah Tahlîliyah
}

\author{
Akhmadul Faruq \\ Sekolah Tinggi Agama Islam Ma'arif, Sampang \\ Email: fauraq.madura@gmail.com
}

Article history: Received: September 11, 2020, Accepted: April 10, 2021, Published: Juni 27, 2021

$$
\begin{aligned}
& \text { ملخص: } \\
& \text { هذا المقال يهدف إلى البحث عن البانتشاسيلا Pancasila) في منظور مقاصد الشريعة. } \\
& \text { تتكون البانتشاسيلا من المبادئ الخمسة، وهي: الربانية المتفردة، والإنسانية العادلة المهذبة } \\
& \text { والمتحضرة، والوحدة الإندونيسية، والشعبية الموجهة بالحكمة والحصافة في الشورى النيابية، } \\
& \text { والعدالة الاجتماعية بين كل المواطنين الإندونيسيين. فهذه الدراسة تعتمد على المنهج } \\
& \text { الاستقائي والتحليلي، وذلك لعرض مبادئ البانتشاسيلا من حيث بيان مفهومها، وتفسيرها } \\
& \text { الرسمي، وتحليلها من المنظور المقاصدي. وقد توصل الباحث إلى تقديم الحلول في التفسير الموافق } \\
& \text { المقاصد الشريعة للبانتشاسيلا. }
\end{aligned}
$$

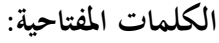

$$
\begin{aligned}
& \text { البانتشاسيلا؛ مقاصد الشريعة؛ مفهومها؛ تفسيرها الرسمي؛ الحلول }
\end{aligned}
$$

\begin{abstract}
:
This article aims to search for Pancasila concept from the perspective of maqashid Sharia. Pancasila is made up of the Five Principles, which are: e.g. belief in the One and Only God, just and civilized humanity, unity of Indonesia, democratic rule that are guided by the strength of wisdom resulting from deliberation and social justice for all Indonesians. This study relies on inductive and analytical method to present the principles of Pancasila in terms of its concept statement, its formal interpretation, and its analysis from the intentional
\end{abstract}


perspective. I have come up with solutions in the interpretation corresponding to the Sharia purposes of Pancasila.

\section{Keyword:}

Pancasila; maqashid Sharia; concept statement; formal interpretation; solutions

إن إندونيسيا دولة كان المسلمون فيها يلعبون دورا مهمّا في استقلالية جمهورية إندونيسيا من قبضة الاستعمار الأجنبي، كما أهم يشكلّون الغالبية العظمى من الشعب الإندونيسي. وعلى الرغم من ذلك إلا أها لا تحكم بالشريعة الإسلامية بشكل كامل شامل، بل كانت الدولة تقوم على أساس البانتشاسيلا (المبادئ الخمسة)، وهي: الربانية المتفردة، والإنسانية العادلة المهذبة والمتحضرة، والوحدة الإندونيسية، والشعبية الموجهة بالحكمة والحصافة في الشورى النيابية، والعدالة الاجتماعية لكل المواطنين الإندونيسيين، فهي أساس فلسفي ومصدر أساسي للقانون الوطني والنظام القانوني لجمهورية إندونيسيا. لذلك، فليست جمهورية إندونيسيا بالبلد الثيوقراطي ولا العلماني ولا الشيوعي، بل هي دولة البانتشاسيا.'

1 Muhammad Taufiq, Akhmadul Faruq, and Ibnu Khaldun, "Implementation of 'The Madina Charter' in a Democratic Country: Indonesia as a Model," in Proceedings of the 6TH International Prophetic Heritage Conference (SWAN 2018) Istanbul, Turkey (Istanbul: SWAN, 2018), 523; Abdul Jalil and Muhammad Taufiq, "Al-Âtsâr Al-Mutarattibah 'Âla PERPPU (Lawâih Al-Hukûmiyyah Al-Badaliyyah) Min Al-Munazhzhamât Al-Mujtama'Iyyah Raqm 2 Li 'Âm 2017 Dlidda Wujûd Hizb Al-Tahrîr Indûnîsiyâ Min Manzhûr Saddi Al-Dzarî'Ah," AL-IHKAM: Jurnal Hukum E Pranata Sosial 14, no. 1 (2019): 144, https://doi.org/10.19105/alihkam.v14i1.1982; Muhammad Taufiq, Filsafat Hukum Islam; Dari Teori Ke Aplikasi, ed. Abd. Jalil, I (Pamekasan: Duta Media, 2019), 219. 
فكلمة البانتشاسيلا مصطلح لدستور الدولة الإندونيسية يرجع أصلها إلى اللغة

السنسكريتية من طبقة برهانا في الهند، وهي مأخودة من بانتشا (panca) تعني خمسة وسيلا (syila) تعني مبدأ أو أساسا، أو سيلا (syiila) تعني نظام الآداب والأخلاق الكريمة المهمة المناسبة. إذا، فإها من الناحية اللغوية اللفظية بمعنى أساس وله خمسة عناصر أو خمسة نظم للسلوك المهمة، وهذا المصطلاح قد اشتهر في عهد ماجاباهيت (Majapahit) في القرن الرابع عشرة وهو مدوّن في كتاب ناجارا كرتاجاما وكتاب سوتاصاما (Empu Prapanca) لامبو فرابانجا (Negara Kertagama) (Sutasoma) لامبو تانتولار (Empu Tantular)، فالبانتشاسيلا يراد بها تنفيذ خمسة آداب وهي على ما يلي:

I Panatipada veramani sikhapadam samadiyani بمعنى منع القتل T r Kameschu micchacara veramani shikapadam samadiyani بمعنى منع

ع. . Musawada veramani sikapadam samadiyani بمعنى منع الكذب ه. Sura meraya masjja pamada tikana veramami يراد به منع السكر أي الكفّ عن شرب الخمر والمخدرات.

وهذه الأسس في الفلسفة الجاوية تعدّ معيارا لتنظيم شؤون حياقم بعد انقراض لهر عهد ماجاباهيت بمصطلاح جاوي "Ma Lima" أي خمة منهيات وهي على "M

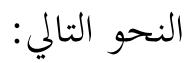
(Mateni) ( القتل

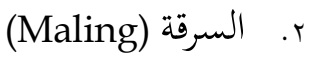




$$
\begin{aligned}
& \text { r. Madon) الزنا } \\
& \text { ع. السكر) (Mabuk) } \\
& \text { ه. القمار (Main) }
\end{aligned}
$$

إن البانتشاسيلا لا يتم سنها إلا كانت وراؤها مقاصد وحكم وأفكار عظيمة تضمن المصالح الشعبية سواء أكانت من شؤوها الداخلية أو علاقاها الخارجية، فالمبادئ الخمسة التي هي مرآة ثقافات الإندونيسيين وعاداتم وسلوكياقم وقيم حياتم عهد ذو قيمة عالية بين الشعب والدولة والحكومة. لذلك، تمدف إلى تكوين المجتمع المدني العدل المزدهر، كما أفها تعدّ وسيلة لتوحيد الشعب الإندونيسي، وهي لا تنصب إلا لمصالح الشعب لتنظيم شؤون الحياة الاجتماعية والاقتصادية والدينية، استجابةً لمتطلبات الجماعة، وسداً لحاجاها، وتقوم بمثابة هندسة اجتماعية للعلاقات داخل الشعب الإندونيسي، إلا يوجد من خلال تطبيقها في الواقع الإندونيسي اضطراب وارتباك في تطبيق المبادئ الإسلامية حتى يقع حدوث الاختلافات الساخنة بين الموافقين لها والمعارضين عليها.

\section{اختيار البانتشاسيلا دستورا للجمهورية الإندونيسية في بداية الاستقلال}

إن سن البانشاسيلا لا يتم إلا وراءها غايات وأهداف ومقاصد مما يحقق مصالح الشعب الإندونيسي من الحرية والعدالة الاجتماعية والمساواة والوحدة في الوطنية، كومن أهم أهداف نصب البانتشاسيلا استقلال الدولة الإندونيسية وشعبها من احتلال الهولنديين واليابانيين، فالبانتشاسلا التي تسري وتتضح في حادثة إلغاء جملة (مع وجوب تنفيذ الشريعة الإسامية وتطبيقها على معتقديها) في ميثاق جاكرتا (

2 Kaelan. M.S. Filsafat Pancasila, Pandangan Hidup Bangsa Indonesia, (Yokyakarta: Paradigma Yokyakarta, 2009), p.2. 


$$
\begin{aligned}
& \text { (Jakarta Charter } \\
& \text { التي تعتبر بابا لتنفيذ الشريعة الإسلامية في هذه الدولة، بعبارات أخرى وتعديل } \\
& \text { Pancasila ) المبادئ الأساسية في ميثاق جاكرتا إلى البانتشاسيلا لدستور } \\
& \varepsilon_{6} \text { (UUD } 1945 \\
& \text { فإذا وقفنا هذا الجو السياسي من النظرية المقاصدية وجدنا أن تقديم } \\
& \text { البانتشاسيلا على الإسلام وميثاق جاكرتا في سن دستور الدولة هو تنازل عن المبادئ } \\
& \text { التي آلت بسبه الويلات والافتراق إلى يومنا هذا. ولسببه ضاعت حقوق المسلمين } \\
& \text { وبالمقارنة مع البلدان المجاورة التي جعلت الإساحم دينا رسميا مثل ماليزيا (Malaysia) } \\
& \text { وبروناي دار السلام (Brunei Darus Salam) وغيرها من البلدان كالسعودية، } \\
& \text { وباكستان، إيران. فإن الحياة الدينية في إندونيسيا من الناحية السياسية مغلوبة من قبل } \\
& \text { غير المسلمين. وفي نفس الأمر، ولتأييد شرعية حكومة إندونيسيا ولتهدئة الجو } \\
& \text { الساخن في السياسة حينئذ، كان منح الرئيس سوكارنو ومنسوبيه من قِبل جمعية هضة }
\end{aligned}
$$

3 Taufiq, Faruq, and Khaldun, "Implementation of 'The Madina Charter' in a Democratic Country: Indonesia as a Model"; Muhammad Taufiq and Masyithah Mardhatillah, "Polygamy in Indonesian Family Law: Analysis of Maqashid Syariah," Journal of Islam in Asia 17, no. 3 (2020); M Mardhatillah and M Taufiq, "The Practice of Amal Masjid in Madura," ... Journal of Multidisciplinary Islamic Education, 2020, 53-72, https://core.ac.uk/download/pdf/354363723.pdf; E. Hariyanto et al., "Effectiveness of the Economic System to Zakat and Waqf for Empowerment of the Ummah in Indonesia," International Journal of Advanced Science and Technology 29, no. 6 (2020).

${ }^{4}$ Al Habib Rizieq Syihab, Wawasan Kebangsaan Menuju NKRI Bersyariah, (Jakarta: Suara Islam Press, 2013). p.4.

5 Imam Mawardi, "Islamic Law and Imperialism: Tracing on The Development of Islamic Law In Indonesia and Malaysia," AL-IHKAM: Jurnal Hukum \& Pranata Sosial 13, no. 1 (2018): 1, https://doi.org/10.19105/alihkam.v13i1.1583. 
العلماء منصب "ولي الأمر" أمرا ضروريا بحيث لا يوجد أفضل من سوكانوا في ذلك الموقف الحرج، ولا يجوز خلو الدولة عن الإمام، جذا القرار يرجع إلى كلام الإمام الغزالي لوالحصني في كفاية الأخيار.^^ وفي هذا القرار اختلافات وانتقادات حادة، بل علّل بعضهم أن هذا القرار مجرد قرار سياسي نفعي مؤقت، فضلا عن كون سوكارنو لا

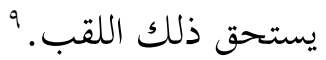
وأما ما قيل إن سبب ذلك الإلغاء هو صدور إنذار من النصارى في شرق إندونيسيا وهم قلة قليلة في إندونيسيا بالانفصال عن إندونيسيا إذا لم تحذف تلك Opsir ( العبارات الإسلامية، وأتى بالمتطلبات والإنذار جند القوات البحرية الياباني IV إلى نائب الرئيس محمد هتا ملحّا له على إنجاز تلك المتطلبات في مساء (kaigun

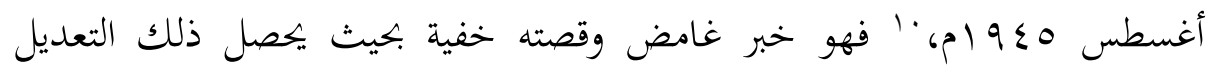
وإلغاء العبارات الإسلامية مع عدم حضور جميع الزعماء الإسلاميين الذين تم توقيعهم على الميثاق ومع إهام شخصية الجند اليباني الذي جاء إلى محمد هتا وعدم التعرف على النصارى في شرق الدولة الذين صرعوا ذاك الإنذار حتى اليوم.

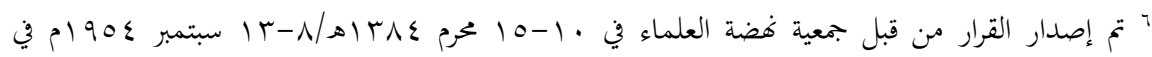

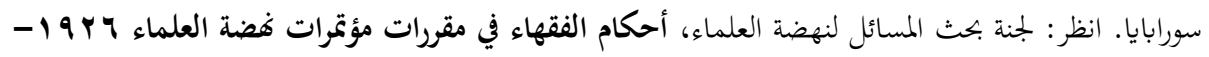

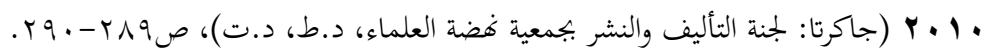

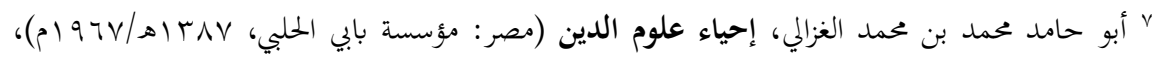

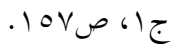
^ أبو بكر بن محمد الحصني الدمشقي، كفاية الأخيار في حل غاية الاختصار (سورابايا: مكتبة أحمد نبهاني،

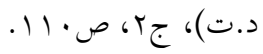
9 انظر: منتهى أرتاليم، فقه التعايش بين المسلمين وغيرهم في إندونيسيا: دراسة مقاصدية (د.م: الجامعة

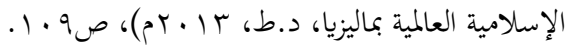

1010 Endang Saifuddin Anshari, Piagam Jakarta 22 Juni 1945 (Jakarta: Gema Insani Press, 1997). p.51. 
ويرى الباحث أن ذلك الإلغاء عبارة عن خيانة البانتشاسيلا، كما أن تلك الحادثة كارثة تاريخية وليست موافقة لمقاصد الشريعة لعدم الشورى التي تتطلب عليها الشريعة الإسلامية، ولأن تقديم البانتشاسيلا على الإسلام وميثاق جاكرتا في سن دستور الدولة هو تنازل عن المبادئ التي آلت بسببه الويلات والافتراق إلى يومنا هذا. ولسببه ضاعت حقوق المسلمين، بل هي اهزام المسلمين تحت القوى الوطنية والنصرانية.

بين التشريع الإسلامي (الشريعة) والتشريع الوضعي (البانتشاسيلا)

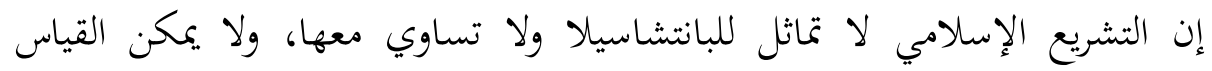

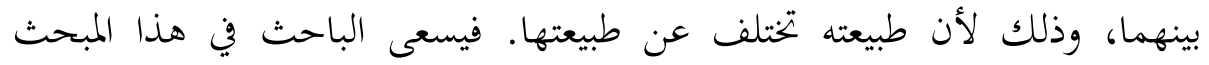
استعراض الاختلافات المتعددة بين التشريع الإسلامي والباتشاسيلا وما يتقف عليهما. فيختلف التشريع الإسلامي عن البانتشاسيلا في ثلاثة أوجه:

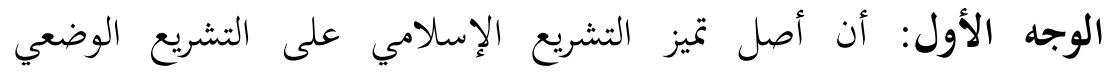

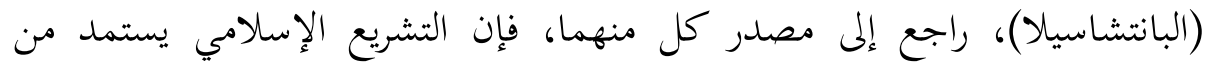

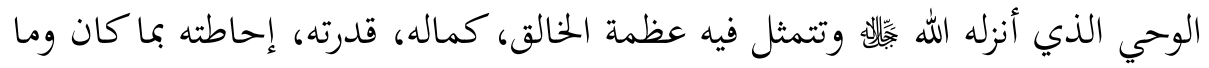

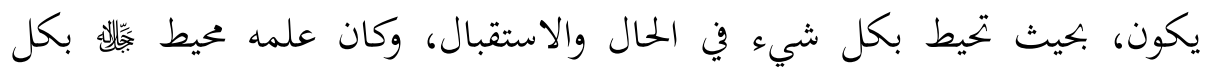

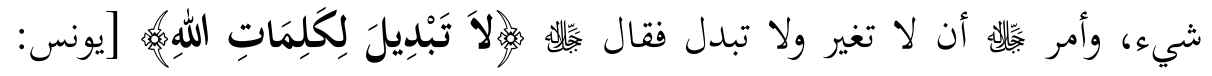

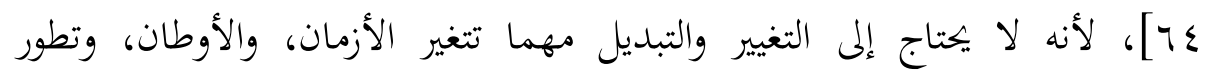

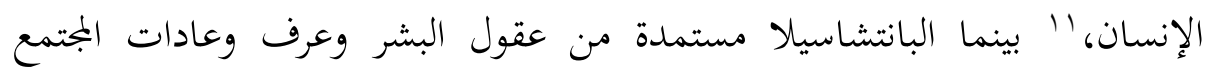

"' عبد القادر عودة، التشريع الجنائي الإسلامي مقارنا بالقانون الوضعي (بيروت: دار الكاتب العربي، د.

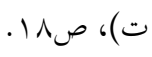


الإندونيسي، ب' ولا كانت البانتشاسيلا تؤخذ منها يتمثل فيها نقص البشر وضعفهم

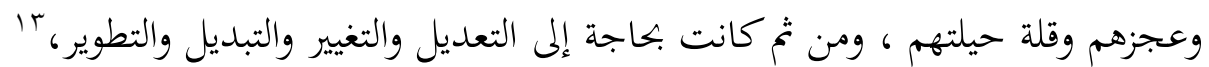
وكلما تطور شعب الدولة إلى درجة غير متوقعة، أو وجدت في حالات غير منتظرة، فالبانتشاسيلا لا يمكن مواكبتها، ولا تحيط بما سيكون وإن أمكن الإلمام بما كان، بل يمكن أن يطرأ عليها النقص والقصور وتدخل فيها الأهواء والنزعات، لكون صانعيها لا يوصفون بالكمال والعصمة.

الوجه الثاين: أن البانتشاسيلا عبارة عن قواعد مؤقتة وضعتها لجنة الإعداد لاستقلال إندونيسيا لتنظيم شؤون جمهورية إندونيسيا وشعبها، وسد حاجاتا، ع' وهي قواعد مؤقتة تمشي مع حال شعبها المؤقت، وتستوجب التغير كلما تغيرت أحوالهم، وأما التشريع الإسلامي فقواعد أثتبها الله مِّلاله على سبيل الدوام لينظّم شؤون الناس أجمعين، فهو يختلف عنها في أن قواعده دائمة ثابتة غير قابلة للتعديل والتبديل

الوجه الثالث: أن لجنة الإعداد لاستقلال إندونيسيا هم الذين صنعوا

البانتشاسيلاج'، ويلوفا بعادات شعب إندونيسي وتقاليدهم وأدياهم، V' والأصل فيها

أها توضع لتنظيم شؤون الدولة وشعبهم لا لتوجيهُهم، ومن ثم تأخرت عنهم وتابعت

لتطورههم، فهي صنع الإندونيسيين. وأما الشريعة الإسلامية فهي من صنع الله الذي

${ }^{12}$ Adian Husaini, Pancasila Bukan Untuk Menindas Hak Konstitusional Umat Islam, (Jakarta: Gema Insani Press, 2012), p.214. p.26.

${ }^{13}$ Ngudi Astuti. Pancasila dan Piagam Madinah. Jakarta: Media Bangsa,

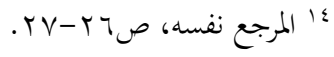

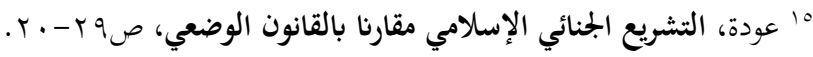

16 Pandji Setijo, Pendidikan Pancasila: Perspektif Sejarah Perjuangan Bangsa (Jakarta: Gramedia Widiasarana Indonesia, 2011), 52-53.

${ }_{17}$ Syihab, Wawasan Kebangsaan Menuju NKRI Bersyariah, p.4. 
أحاط علمه كل شيء وأتقنه خلقه، فالشريعة ومقاصدها لا توضع لتنظيم شؤون الجماعة المعينة فحسب، وإنما المقصود من التشريع الإسلامي تكوين الأفراد الصالحين

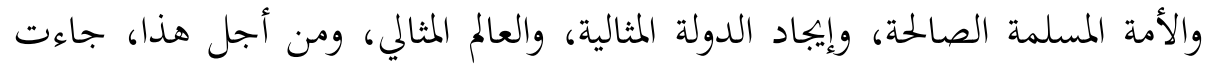

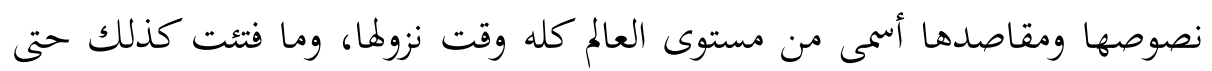
الآن. 11 إن

بناء على ما سبق، يظهر للباحث أهم المميزات التي تميز الشريعة عن البانتشاسيلا؛ بخمس ميزات جوهرية: 1. الإلهية: إن الشريعة الإسلامية شريعة إلهية، بينما البانتشاسيلا شريعة وضعية.

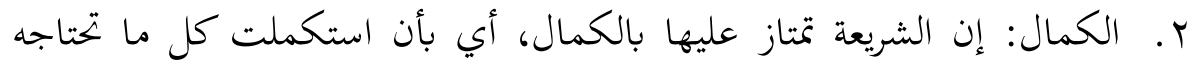

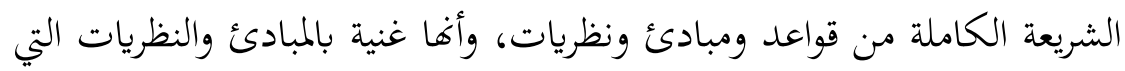
تكفل سد حاجات الناس أجمعين في الحاضر القريب والمستقبل البعيد.

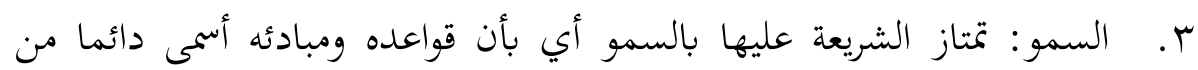

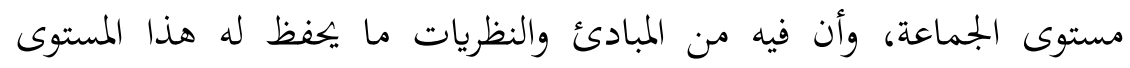

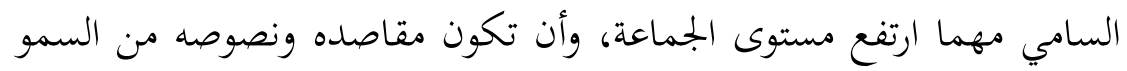

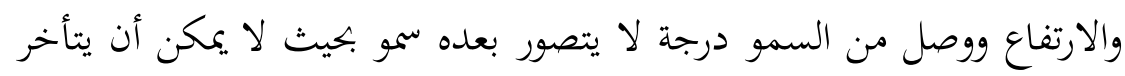
في وقت أو عصر ما عن مستوى الجماعة. ع. ـ الدوام: إنا تمتاز عليها بالدوام والثبات والاستقرار، فنصوصها لا تقبل التعديل

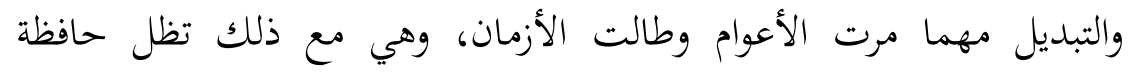
لصلاحيتها في كل زمان ومكان.

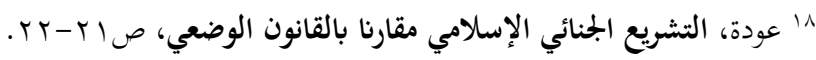

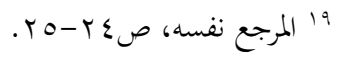


ه. المرونة والعموم: ‘r أن تكون قواعد الشريعة ونصوصها من المرونة والعموم إلى آخر حدود العموم والمرونة بحيث تتسع لحاجات الجماعة مهما تقدمت

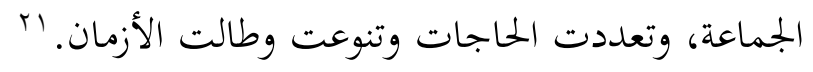

إن هناك جامعاً بين مفهومي البانتشاسيلا والشريعة الإسلامية، وهو يمكن القول بأن المبدأين كلاهما عبارة عن القواعد والمبادئ التي تهدف إلى تحقيق المصالح ودرء المفاسد، مع العلم أن مقاصد الشريعة في حقيقتها تتجاوز كوفها مبادئ مجردة إلى كوغها خطابا للناس كافة، وكما أن كليهما وُضعا لتنظيم الجماعة. فتبين مما سبق أن البانتشاسيلا إذا كان معانيها ومحتواها توافق لمقاصد الشريعة ويمكن بها تطبيق الشريعة في جمهورية إندونيسيا فلا مانع من إطلاقها شرعا، لأن نوط الأحكام الشرعية تتعلق بالحقائق والمعاني لا بالألفاظ والمباني، بr وأما إذا كانت مخالفة للشريعة، سواء كانت من النظريات التي تتفق عليها الدولة، أو المسائل المختصة بها فهي غير معتبرة.

الرؤية المقاصدية في المبادئ الحمسة (البانتشاسيلا) إن سن البانتشاسيلا دستورا للدولة ليس فيه بأس ما دامت تراعى مقررات ثابتة في الشريعة الإسلامية ومقاصدها الكلية العامة، بr كما يعبر ابن الجوزية عن مثل هذا بأنه

r.r. Fممد الطاهر الميساوي، الشيخ محمد الطاهر بن عاشور وكتابه مقاصد الشريعة الإسلامية (د. م:

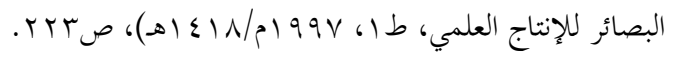

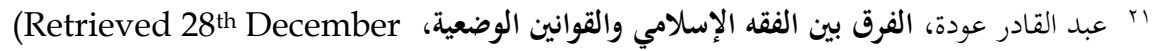

.2018). > https://etudes-islamic.blogspot.my/2016/02/blog-post_53.html>

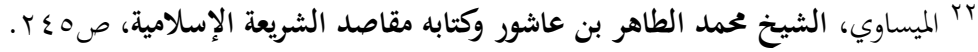

23 Taufiq, Faruq, and Khaldun, "Implementation of 'The Madina Charter' in a Democratic Country : Indonesia as a Model." 


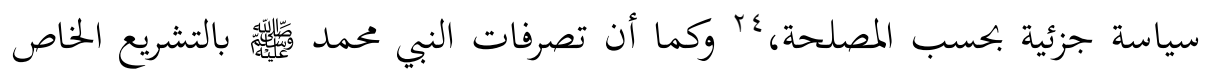
هي شرع غير ملزم على سبيل الدوام في ذاته وملزم في منهجه ومقاصده وغاياته

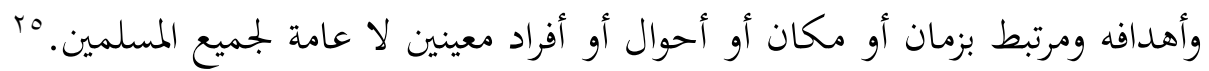
فحاول الباحث أن يسعى تقديم الحلول في التفسير الموافق المقاصد الشريعة لبانتشاسيلا.

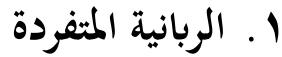

يراد بها الشهادة بأن الله تعالى هو الواحد الأحد، المطلق المتعالي رب كل ما في الوجود

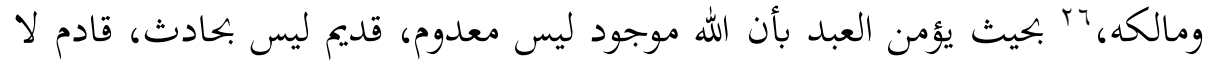

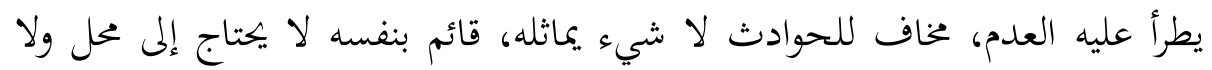
مخصص، واحد لا مشرك له في ذاته ولا صفاته ولا أفعاله، القادر، والمريد، والعالم،

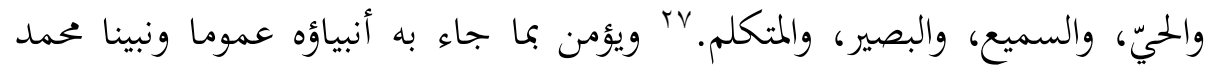

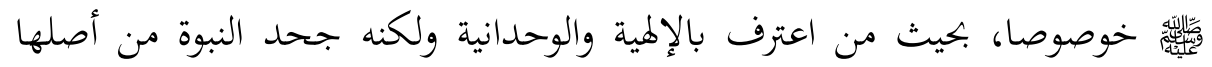

عُ ابن قيم الجوزية، الطرق الحكمية في السياسة الشرعية، تحقيق: نايف بن أحمد الحمد (جدة: دار عالم

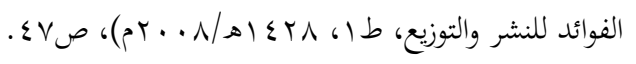

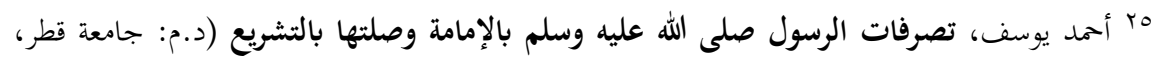

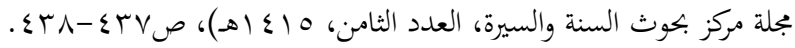

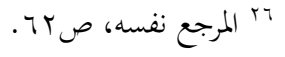

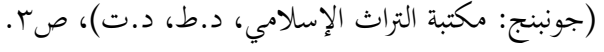

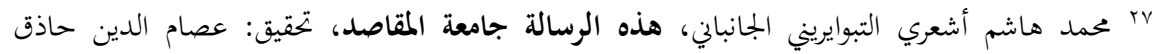




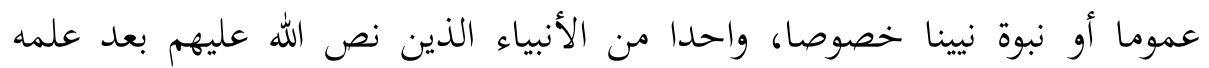

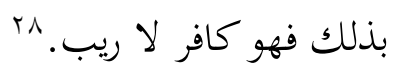

هذا المبدأ تتيح الحكومة للشعب حرية الاعتقادات بحيث تعترف بتعدد الأديان. في الجمتمع الإندونيسي مع امكان التعايش السلمي بين أفراده والحفاظ على هوية المجتمع وخصوصيته مع مراعاة المبادئ الإسلامية، وتترك كل محاولات الإجبار والإكراه على تغيير الدين أو المعتقد أو مذهب، لا بمعنى أن تقرر الضالين والكافرين على كفرهم جr كما لا بد على الحكومة من حفظ الدين الإسلامي بحيث تقيم أركانه وأن تثبت قواعده من العمل به والجهاد من أجله والدعوة إليه والحكم به، وأن تدفع كل ما يخالف دين الإسلام من الأهواء والبدع والمنكرات. ·r وبهذا المبدأ يجيب على كل فرد أن يجعل شريعة الله يقالهالم مرجعا أساسيا ومصدرا رئيسيا في كل مجال حياته سواء كان ذلك يتعلق بالفرد أم بالأسرة أم بالمجتمع والأمة أو بالوطن والبلد وكذا يلزم على الحكومة وممثلي الشعب في البرلمان أن لا تتخذوا قرارت وقوانين إلا موافقة للشريعة ومقاصدها. 'ب وهذا المبدأ أكد أن الإسلام دين التوحيد: توحيد الإله وتوحيد الرسل في التيشير لهذا الدين الواحد، فهو دين الوحدة بين العبادة والمعاملة، والعقيدة والشريعة، والروحيات والماديات والقيم الاقتصادية والمعنوية، وعن

$$
\begin{aligned}
& \text { ^r أشعري، هذه الرسالة جامعة المقاصد، ص rا با. }
\end{aligned}
$$

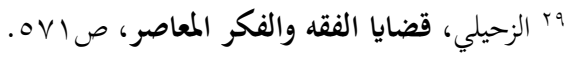

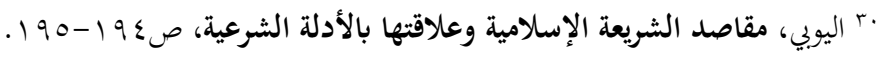

31 Jalil and Taufiq, "Al-Âtsâr Al-Mutarattibah 'Âla PERPPU (Lawâih AlHukûmiyyah Al-Badaliyyah) Min Al-Munazhzhamât Al-Mujtama'Iyyah Raqm 2 Li “Âm 2017 Dlidda Wujûd Hizb Al-Tahrîr Indûnîsiyâ Min Manzhûr Saddi Al-Dzarî'Ah.” 
تلك الوحدة تصدر تشريعاته وفرائضه وتوجيهاته وحدوده وقواعده في سياسية الحكم

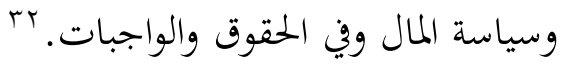

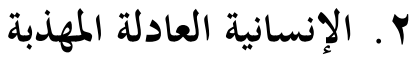

المراد بالإنسانية بجموعة من الأفكار الغالية والتصرفات الحميدة التي تصدر عن الفرد

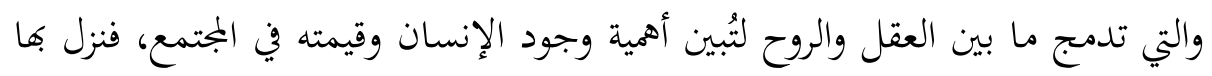
الإنسان في مرتبة عالية ويكنه بعقله وبضميره إيجاد قيم ونظم إيجابين. فلا تتم الإنسانية العادلة إلا فيها مبادئ الحرية والتسامح والمساوة، فالحرية هي الإباحة التي لئي

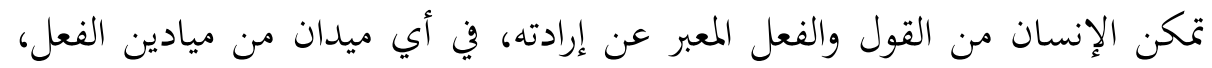

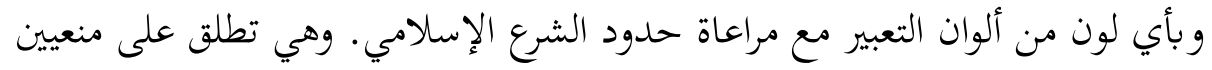

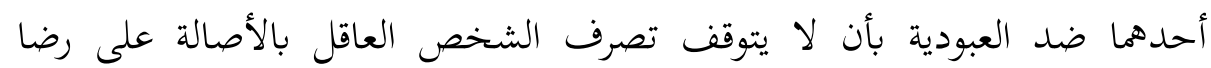

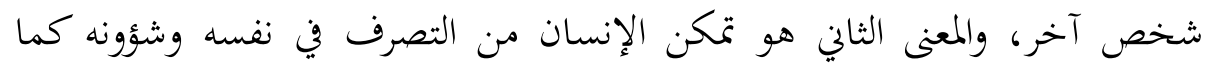

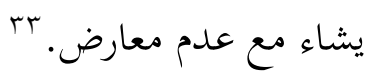
فالحرية بالمعنى الثاني تتعلق مظاهرها بأصول الناس من اعتقاداتم وتصرفاتم من أقوالهم وأفعالم، فحرية الاعتقادات قد تقدم بحثه في المبدأ الأول، وأما الحرية القولية فيقصد بها التصريح بالرأي والاعتقاد في ميدان الإذن الشرعي مثل حرية العلم والتعليم والتأليف، كما أن حرية الأعمال إما في عمل المرء في خويصته وإما في عمله الماس ميساس

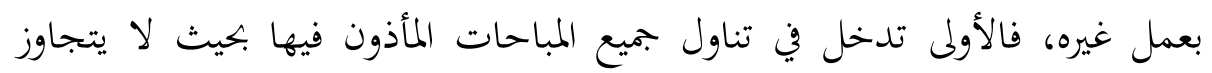

\footnotetext{
rrr سيد قطب، العدالة الاجتماعية في الإسلام (بيروت: دار الشروق، د.ط، 1 إ اهـ/990 1م)، ص7 Y.
}

33 Moh. Zahid and Moh Hasan, "The Existence of Wasathiyyah Islam in Madura (An Analysis of Urban Society's Acceptance of Islamic Content on Social Media)," AL-IHKAM: Jurnal Hukum E Pranata Sosial 13, no. 2 (2018): 382, https://doi.org/10.19105/al-ihkam.v13i2.1875. 
العمل عامله ويكون العمل المؤثر في عمل غيره لا يُنشأ ضرارا عليه مثل اختيار الملابس والمطاعم والمساكن، وأما من حرية الأعمال التي تتعلق بأعمال الغير فما يجيب به المرء على نفسه بموجب هذه الحرية من التزامات وإجراء العقود لمصلحة يراها، گَ فإلزام الشخص نفسَه ذو تأثير حرية العمل الموجب به حقا لغيره عليه على تفاصيل العقود التي بتب بالتعاقد القولي والتي لا بتجب إلا بالشروع في العمل. ro والتسامح هو احترام متبادل بين الشعب الإندونيسي بعضهم بعضا، والاستعداد لتقبل المختلف واحترام البشر المختلفين من حيث المظهر، ولون البشرة، والجنس، والديانة والمعتقدات مع عدم بجاوز الحد الشرعي. بr والمساواة يراد بها أن يقام جميع الشعب الإندونيسي أمام القضاء والحكم وفي الحقوق والواجبات على سواء من غير تمييز ولا تفريق بينهم إلا عند وجود مانع من موانع المساواة، والمراد بها العوارض التي إذا تحققت تؤدي إلى إلغاء حكم المساواة

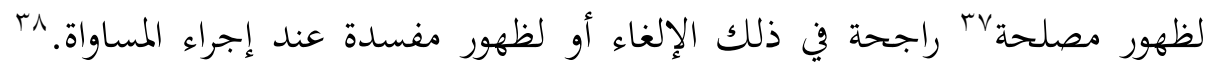
واعتبار هذه الموانع يكون في الهدف الذي من حقها منع المساواة ليس على اطلاقها، فالعوارض التي تتعتبر موانعَ إجراء مبدأ التساوى في بعض الأحكام الشرعية تنقسم إلى أربعة أقسام، وهي على النحو التالي:

${ }^{34}$ Muhammad Taufiq, "A Critique against the Perspective of Al-Thufy on the Contradiction of Maslahat and the Holy Text," Millati: Journal of Islamic Studies and Humanities 5, no. 2 (2020): 121-28, https://doi.org/10.18326/mlt.v5i2.121-128.

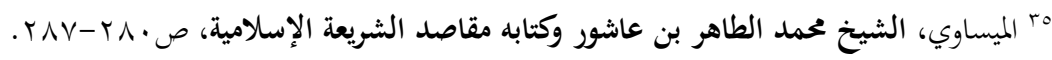

36 Maimun Maimun, "Islam Nusantara in Islamic Law Epistemology Perspective," Al-Ihkam: Jurnal Hukum \& Pranata Sosial 11, no. 2 (2017): 392, https://doi.org/10.19105/al-ihkam.v11i2.779.

37 Taufiq, "A Critique against the Perspective of Al-Thufy on the Contradiction of Maslahat and the Holy Text."

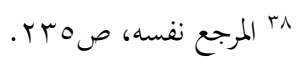




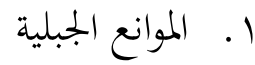

هذه الموانع تقتصر على موجبات أصل الخلقة مثل إبطال حكم التساوي بين الرجل

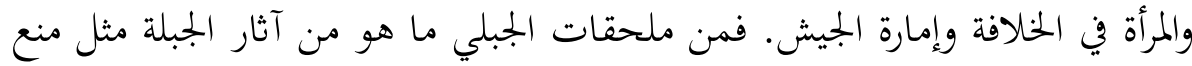
التساوي بينهما في النفقة بحيث يجب ذلك على الرجل (الزوج) لما تقرر فن العوائد من كونه هو الكاسب للأسرة، وصفات تكتسب ناشئة عن قابلية وعن سعي، وترك آثار آثار

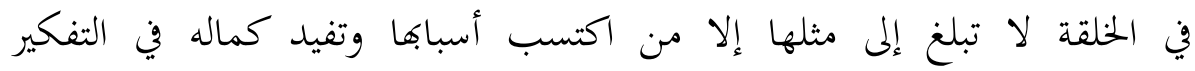
والإحساس، مثل عدم المساواة بين العالم وغيره في الصلاحية لإدراك المدركات الخفية

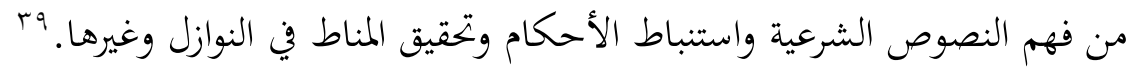
r. الموانع الشرعية ويراد بها ما كان تأثيرها بتعيين التشريع الحق، لأنه لا يستند إلا إلى حكم وعلل

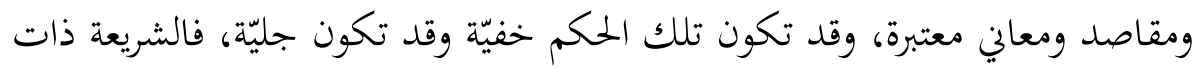

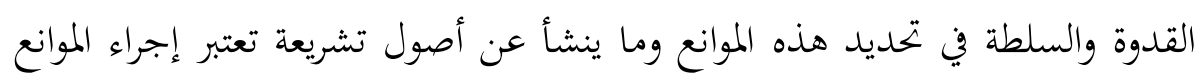

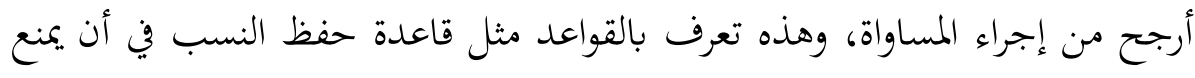

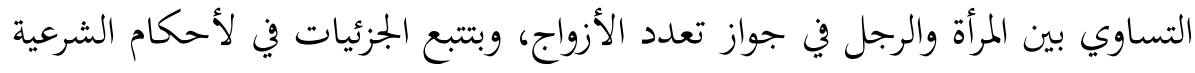

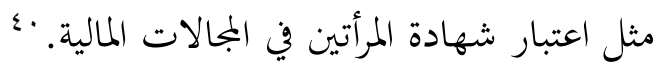
r. الموانع الاجتماعية

هذه الموانع غالبها تبني على ما فيه المصالح الاجتماعية يرجع بعضها إلى المعاني

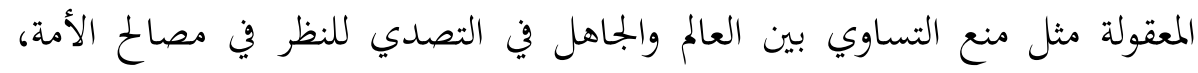

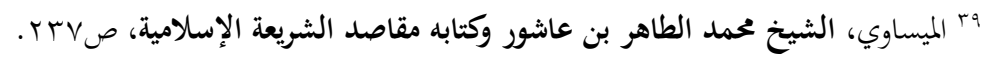

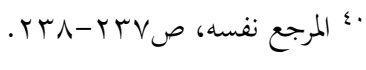


وبعضها الآخر إلى عرف الناس وعاداتم التي تأصلت فيهم مثل منع المساواة العبيد

للأحرار في قبول الشهادة، وكما أغا توجد كثيرا في المجالات الاجتهادية. '؛ ع. ـ ـ الموانع السياسية

وهي الأحوال التي لما تأثير في سياسة الأمة، فتتطرق إلى منع حكم المساواة بين أصناف، أو أفراد، أو في المجالات والأحوال الخاصة، ولا يكون ذلك إلا لتحقق

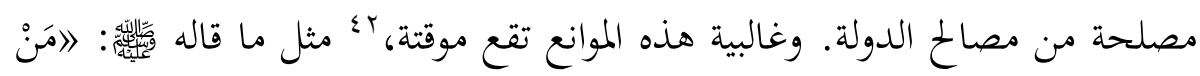

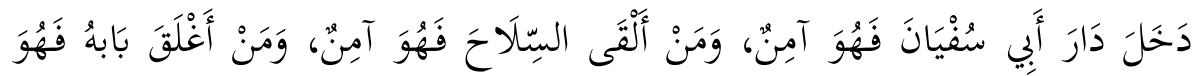

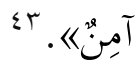

\section{ب. الوحدة الإندونيسية}

فالوحدة في البانتشاسيلا تنبنى على شعار "بينيكا تونغال إيكا ( Bhinneka Tunggal "Ika إلى وحدة يجمعهم فيها الوطنية الإندونيسية وتراد بها وحدة الدستور والسياسة والاقتصاد والشؤون الاجتماعية والثقافة والأمن في حكومة إندونيسيا، وقهدف إلى تحقيق الحياة الدولية الحرة في الدولة المستقلة ذات السيادة الكاملة، وحماية الشعب الإندونيسي وتطوير رفاهيتهم وتثقيف حياهم وتحقيق العدالة الاجتماعية والمحافظة على

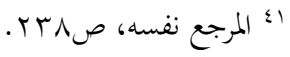

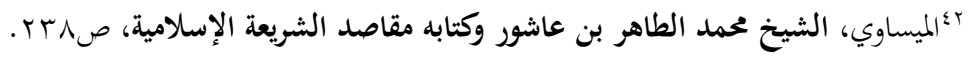

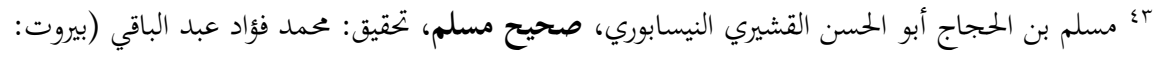

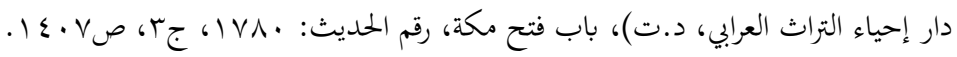


السلام العالمي. گُهي ضد الاختلاف والتفرقة والانتقاء وبها تحقق التكافل العامْ؛ بأن

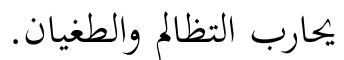

\section{ع. الشعبية الموجهة بالحكمة والحصافة في الثورى النيابية}

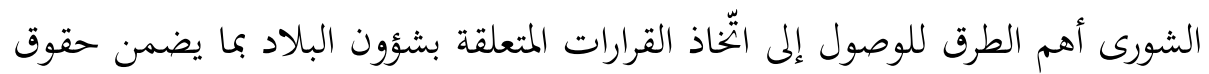

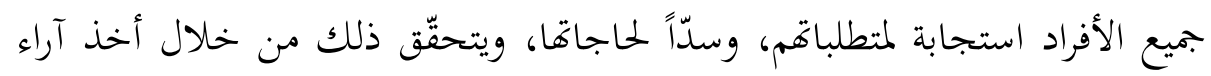

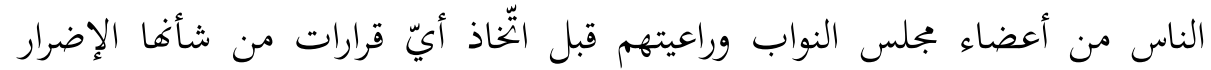

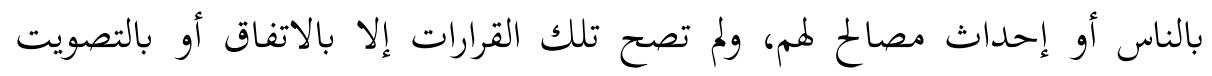

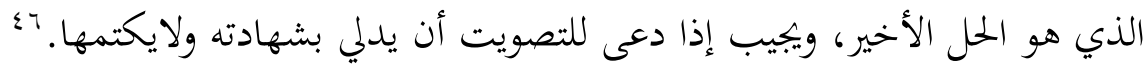
إن للشورى حدودا لا تتعداها بحيث تكون سلطة مجالس النواب غير مطلقة،

وإنما هي مقيدة بالقواعد والضوابط والمبادئ والأحكام الشرعية التي شرعها الله، فلا

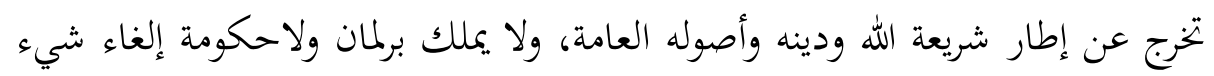

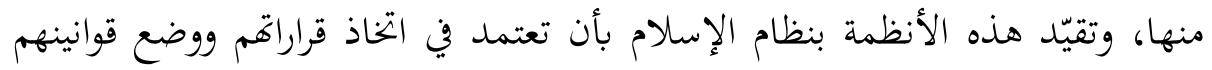

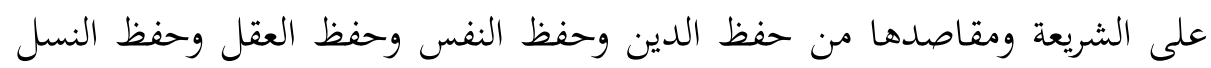
وحفظ المال وحفظ الدولة والعدالة والأمن وحفظ نظام الأمة، فيكون الشعب

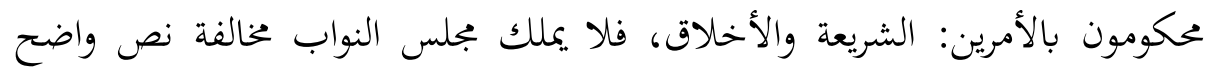

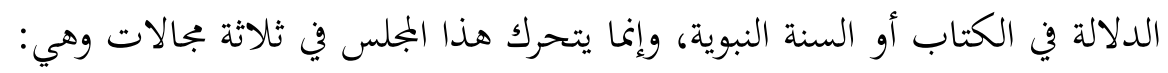
1. في ما لا نص فيه، بحيث لم يرد فيه دليل شرعي نقلي من القرآن والسنة.

${ }_{44}$ Ahmad Hariadi, 45 Butir Nilai Luhur Pancasila Bagian Ajaran al-Quran. (Jakarta: Yayasan Kebangkitan Kaum Muslimin, 2015). pp.42-64.

${ }^{45}$ Hariyanto et al., "Effectiveness of the Economic System to Zakat and Waqf for Empowerment of the Ummah in Indonesia."

$$
\text { ד؛ القرضاوي، من فقه الدولة، صVr. }
$$




$$
\begin{aligned}
& \text { r ا ب. فيما فيه نص ظني الدلالة. } \\
& \text { r. ي إطار التنفيذ أي إصدار القوانين واللوائح التنظمية والقرارات. \؛ } \\
& \text { ويجب على المرشح للبرلمان في إيطار الديمقراطة البانتشاسيلوية أن يكون حفيظا } \\
& \text { عليما وقويا أمينا وحكيما عدلا، كما يشترط في الناخب العدالة وحسن السيرة. ويجوز } \\
& \text { لكل فرد من الشعب أن ينصحهم ويأمرهم بالمعروف وينهاهم عن المنكر. 1؛ }
\end{aligned}
$$

\section{هـ العدالة الاجتماعية لكل المواطنين الإندونيسيين}

إن العدالة الاجتماعية هي عدالة إنسانية شاملة لكل جوانب الحياة الإنسانية وليس جررد عدالة اقتصادية محددة، لأن الحياة البشرية ليست علاقات مقطوعة، وإنما هي تراحم وتواد وتعاون وتكافل بين المسلمين في إندونيسيا على وجه خاص، وبين جميع أفراد الشعب من النصارى واليهود والبوذيين وغيرهم على وجه عام، فللعدالة الاجتماعية ركيزتان وهما: الوحدة المطلقة التي تتناسق بين مقوامات الإسلام، والتكافل العام بين المواطنين الإندونيسيين. فالوحدة ضد التجزيء والانتقاء، وأما التكافل ضد التظالم والطغيان. فليس في العدالة الاجتماعية قبول طغيان الفرد على الجماعة، ولا إظهار ظلم الجماعة على فطرة الفرد ومواهبه. بناء على ما سبق، فحفظ كرامة الفرد واجب ليتمكن له من أن يبدع وأن يستثمر كامل طاقته مقررا مبدأ تكافؤ الفرض والعدل بين الشعب، ولكنه ترك ججالا للتفاضل بالعمل والجههد. لهذا لا تفرض فيها المساوة الحرفية في المال. لأن تحصيله تبع لاستعدادات، كما أن العدل المطلق يؤدى

$$
\begin{aligned}
& \text { V؛ الزحيلي، قضايا الفقه والفكر المعاصر، صه 10 ه-7 10. } \\
& \text { ^؛ القرضاوي، من فقه الدولة، صجr }
\end{aligned}
$$


إلى تفاوت الأرزاق مع تحقيق العدالة الإنسانية. وأما أساس هذه العدالة ومبادئها

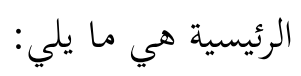

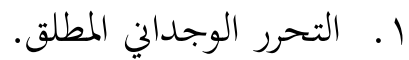
r. المساواة الإنسانية الكاملة. r. التكافل الاجتماعي الوطيد الوثيق بين المواطنين الإندونيسيين داخلها وخارجها.

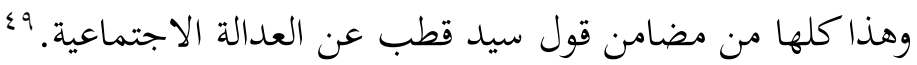

اتضح عند الباحث أن وجه الاختلاف والاتفاق بين البانتشاسيلا والشريعة الإسلامية، فتختلف الشريعة عن البانتشاسلا بثلاثة أوجه أساسية؛ أولها: إن الشريعة الإسلامية تستنبط من الوحي إلهي، بينما البانتشاسيلا تستمد من عقول البشر وعرف وعادات المجتمع الإندونيسي. ثانيها: إن الشريعة وضع إلهي، بينما البانشاسيلا وضع بشري. ثالثها: تمتاز الشريعة عن البانتشاسيلا في الكلية والجزئية، فالشريعة لا تقبل

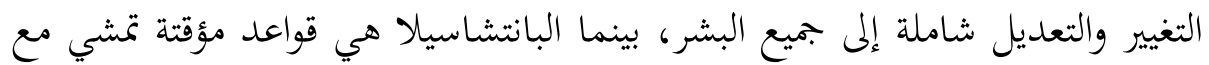
حال شعبها المؤقت، وتستوجب التغير كلما تغيرت حالمم. فأما الوجه الجامع بين مفهومي البانتشاسيلا والشريعة الإسلامية، فيمكن القول بأن كلا المبدأين عبارة عن

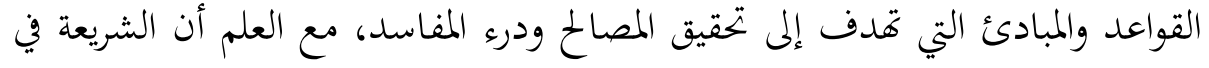
حقيقتها تتجاوز كوها مبادئ مجردة إلى كوغا خطابا للناس كافة، وكما أن كليهما وُضعا لتنظيم الجماعة. فلا بد للباحث سعى تقديم الحلول في التفسير الموافق المقاصد الشريعة للبانتشاسيلا. كما في المبدأ الأول تتيح الحكومة للشعب حرية الاعتقادات 

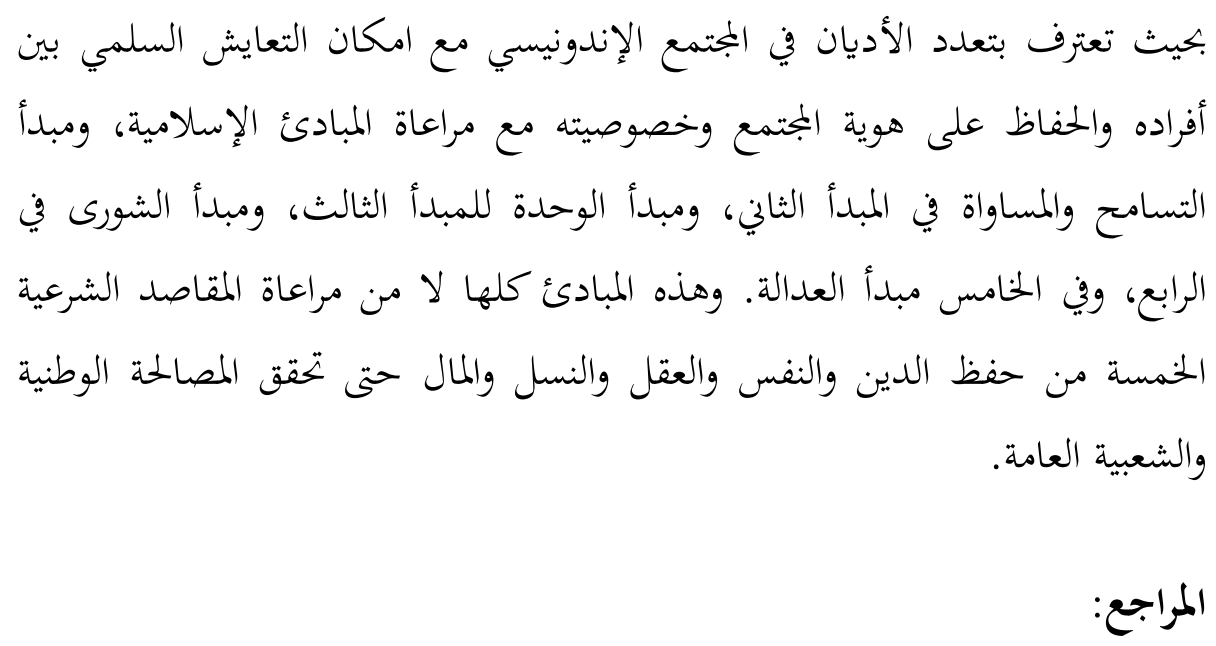

Ahmad Hariadi, 45 Butir Nilai Luhur Pancasila Bagian Ajaran al-Quran. (Jakarta: Yayasan Kebangkitan Kaum Muslimin, 2015). pp.42-64.

Al-Dimasyqi, Abu Bakar Muhammad. Kifayatu al-Akhyar fi Hilli Ghayati al-Ikhtishar. Surabaya: Maktabah Ahmad Nabhani, Vol. 2.

Al-Ghazali, Abu Hamid Muhammad. Ihya' Ulum al-Din. Egypt: Muassasah Bab al-Halabi, Vol. 1, 1967.

Al-Jauziyah, Ibn Al-Qayyim. al-Thuruq al-Hukmiyah fi al-Siyasah alSyar'iyyah. Jeddah: Dar 'alami al-Fawaid, Vol. 1, 2008.

Al-Misawi, Muhammad al-Thaher, Al-Syaikh Muhammad Al-Thaher bin Asyur wa Kutubuhu Maqashid al-Syariah al-Islamiyah. Al-Bashair li Intaji al-Ilmi, Vol. 1, 1997.

Al-Qardawi, Yusuf, Min Fighi al-Daulah fi al-Islam. Beirut: Dar alSyoroq, vol. 1, 1997.

Al-Yubi. Maqashid al-Syariah wa 'alaqatuha bi al-Adillah al-Syar'iyyah. Riyadh: Dar al-Hijrah, Vol. 1, 1418.

Al-Zuhaili. Qadhaya al-Fiqh wa al-Fikr al-Mu'ashir.

Astuti, Ngudi. Pancasila dan Piagam Madinah. Jakarta: Media Bangsa.

Asyari, Muhammad Hasyim, Hadzihi Al-Risalah Jami'ah al-Maqashid, Tahqiq Ishomuddin Hadziq, Jombang: Maktabah al-Turats alIslami.

Audah, Abd al-Qadir, Al-Farqu Baina al-Figh al-Islami wa al-Qawanin Al-Wadh'iyyah, (Retrieved 28th December 2018). <https:/ / etudesislamic.blogspot.my/2016/02/blog-post_53.html>. 
Audah, Abd Al-Qadir. Al-Tasyri' al-Jina'i al-Islami Muqaranan bi alQanun al-Wadh'i. Beirut: Dar al-Kotob al-Arabi.

Endang Saifuddin Anshari. Piagam Jakarta 22 Juni 1945. Jakarta: Gema Insani Press, 1997.

Hariyanto, E., M. Taufiq, Z. Abidin, M. Ulum, and Maimun. "Effectiveness of the Economic System to Zakat and Waqf for Empowerment of the Ummah in Indonesia." International Journal of Advanced Science and Technology 29, no. 6 (2020).

Husaini, Adian. Pancasila Bukan Untuk Menindas Hak Konstitusional Umat Islam, Jakarta: Gema Insani Press, 2012.

Jalil, Abdul, and Muhammad Taufiq. “Al-Âtsâr Al-Mutarattibah 'Âla PERPPU (Lawâih Al-Hukûmiyyah Al-Badaliyyah) Min AlMunazhzhamât Al-Mujtama'Iyyah Raqm 2 Li 'Âm 2017 Dlidda Wujûd Hizb Al-Tahrîr Indûnîsiyâ Min Manzhûr Saddi AlDzarî'Ah." AL-IHKAM: Jurnal Hukum \& Pranata Sosial 14, no. 1 (2019): 144. https://doi.org/10.19105/al-ihkam.v14i1.1982.

Kaelan. M.S. Filsafat Pancasila, Pandangan Hidup Bangsa Indonesia. Yokyakarta: Paradigma Yokyakarta, 2009. p.2.

Lajnah Bahstul Masail. Ahkamu al-Fuqaha' fi Muqarrati Mu'tamarat Nahdlatul Ulama 1926-2010. Jakarta: LTN NU.

Maimun, Maimun. "Islam Nusantara in Islamic Law Epistemology Perspective." Al-Ihkam: Jurnal Hukum \& Pranata Sosial 11, no. 2 (2017): 392. https:// doi.org/10.19105/al-ihkam.v11i2.779.

Mardhatillah, M, and M Taufiq. "The Practice of Amal Masjid in Madura." ... Journal of Multidisciplinary Islamic Education, 2020, 53-72. https:/ / core.ac.uk/download/pdf/354363723.pdf.

Mawardi, Imam. "Islamic Law and Imperialism: Tracing on The Development of Islamic Law In Indonesia and Malaysia." $A L-$ IHKAM: Jurnal Hukum \& Pranata Sosial 13, no. 1 (2018): 1. https:/ / doi.org/10.19105/al-ihkam.v13i1.1583.

Muslim, Al-Hajjaj Abu Al-Hasan al-Nisapuri. Shahih Muslim. Beirut: Dar Ihya al-Turost al-Arabi. Vol. 3.

Qutub, Sayyid, al-Adalah al-Ijtima'iyah fi al-Islam. Beirut: Dar AlSyuruq, 1995.

Setijo, Pandji. Pendidikan Pancasila: Perspektif Sejarah Perjuangan Bangsa. Jakarta: Gramedia Widiasarana Indonesia, 2011.

Syihab, Rizieq. Wawasan Kebangsaan Menuju NKRI Bersyariah. Jakarta: Suara Islam Press, 2013. 
Taufiq, Muhammad. "A Critique against the Perspective of Al-Thufy on the Contradiction of Maslahat and the Holy Text." Millati: Journal of Islamic Studies and Humanities 5, no. 2 (2020): 121-28. https://doi.org/10.18326/mlt.v5i2.121-128.

- - - . Filsafat Hukum Islam; Dari Teori Ke Aplikasi. Edited by Abd. Jalil. I. Pamekasan: Duta Media, 2019.

Taufiq, Muhammad, Akhmadul Faruq, and Ibnu Khaldun. "Implementation of 'The Madina Charter' in a Democratic Country: Indonesia as a Model." In Proceedings of the 6TH International Prophetic Heritage Conference (SWAN 2018) Istanbul, Turkey, 523. Istanbul: SWAN, 2018.

Taufiq, Muhammad, and Masyithah Mardhatillah. "Polygamy in Indonesian Family Law: Analysis of Maqashid Syariah." Journal of Islam in Asia 17, no. 3 (2020).

Yosof, Ahmed, Tasharrufatu al-Rasul Shallallahu Alaihi Wa Sallam bi alImamati wa Shilatuha bi al-Tasyri'. Qatar: Jami'atu Qatar, Majallah Markaz Buhus al-Sunnah wa al-Sirah, Ed. VIII, 1415.Hariyanto, E., M. Taufiq, Z. Abidin, M. Ulum, and Maimun. "Effectiveness of the Economic System to Zakat and Waqf for Empowerment of the Ummah in Indonesia." International Journal of Advanced Science and Technology 29, no. 6 (2020).

Jalil, Abdul, and Muhammad Taufiq. "Al-Âtsâr Al-Mutarattibah 'Âla PERPPU (Lawâih Al-Hukûmiyyah Al-Badaliyyah) Min AlMunazhzhamât Al-Mujtama'Iyyah Raqm 2 Li 'Âm 2017 Dlidda Wujûd Hizb Al-Tahrîr Indûnîsiyâ Min Manzhûr Saddi AlDzarî' Ah." AL-IHKAM: Jurnal Hukum E Pranata Sosial 14, no. 1 (2019): 144. https:// doi.org/10.19105/al-ihkam.v14i1.1982.

Maimun, Maimun. "Islam Nusantara in Islamic Law Epistemology Perspective." Al-Ihkam: Jurnal Hukum \& Pranata Sosial 11, no. 2 (2017): 392. https:/ / doi.org/10.19105/al-ihkam.v11i2.779.

Mardhatillah, M, and M Taufiq. "The Practice of Amal Masjid in Madura." ... Journal of Multidisciplinary Islamic Education, 2020, 53-72. https:/ / core.ac.uk/download/pdf/354363723.pdf.

Mawardi, Imam. "Islamic Law and Imperialism: Tracing on The Development of Islamic Law In Indonesia and Malaysia." $A L-$ IHKAM: Jurnal Hukum \& Pranata Sosial 13, no. 1 (2018): 1. https://doi.org/10.19105/al-ihkam.v13i1.1583.

Taufiq, Muhammad. "A Critique against the Perspective of Al-Thufy 
on the Contradiction of Maslahat and the Holy Text." Millati: Journal of Islamic Studies and Humanities 5, no. 2 (2020): 121-28. https:// doi.org/10.18326/mlt.v5i2.121-128.

- - - Filsafat Hukum Islam; Dari Teori Ke Aplikasi. Edited by Abd. Jalil. I. Pamekasan: Duta Media, 2019.

Taufiq, Muhammad, Akhmadul Faruq, and Ibnu Khaldun. "Implementation of 'The Madina Charter' in a Democratic Country: Indonesia as a Model." In Proceedings of the 6TH International Prophetic Heritage Conference (SWAN 2018) Istanbul, Turkey, 523. Istanbul: SWAN, 2018.

Taufiq, Muhammad, and Masyithah Mardhatillah. "Polygamy in Indonesian Family Law: Analysis of Maqashid Syariah." Journal of Islam in Asia 17, no. 3 (2020).

Zahid, Moh., and Moh Hasan. "The Existence of Wasathiyyah Islam in Madura (An Analysis of Urban Society's Acceptance of Islamic Content on Social Media)." AL-IHKAM: Jurnal Hukum \& Pranata Sosial 13, no. 2 (2018): 382. https://doi.org/10.19105/alihkam.v13i2.1875.

Zaim, Muntaha Artalim. Fikih Al-Ta'ayus Baina al-Muslimin wa Gairihim fi Indunesia: Dirasah Maqashidiyah. Al-Jami'ah alIslamiyah al-Alamiyah Malaysia, 2013. 